http://jmscr.igmpublication.org/home/ ISSN (e)-2347-176x ISSN (p) 2455-0450

crossref DOI: https://dx.doi.org/10.18535/jmscr/v8i8.47

\title{
The Role of Intra-Articular Viscosupplementation in Treatment of Early Osteoarthritis of Knee: An Interventional Study
}

\author{
Authors \\ Dr Shikha Dhaundiyal ${ }^{1}$, Dr Deepak Joshi ${ }^{2}$ \\ ${ }^{1}$ Senior Resident (MD Sports Medicine) Gold Medalist Sports Injury Centre, VMMC \& SJH \\ ${ }^{2}$ Senior Specialist Sports Injury Centre, VMMC \& SJH
}

\section{Introduction}

$\mathrm{OA}$ is a degenerative joint disease and most common form of arthritis worldwide. Kneeis the most common joint. Women are most commonly affected. The prevalence increases with age and become significant after 50 years of age. ${ }^{1}$

$\mathrm{OA}$ is characterized by pain and progressive joint dysfunction resulting from destruction of the cartilage and subchondral bone, with reduction of the joint space, inflammation/synovitis and formation of periarticular osteophytes. Among the major joints, the knees are the most common to be affected. $^{2}$

$\mathrm{OA}$ is the eleventh highest contributor to global disability. ${ }^{3-4}$

OA of knee may be classified as either primary or secondary. Primary OA is idiopathic, most probably natural wear and tear, while in secondary OA there is a link to a specific cause, such as previous injury to a joint, altered biomechanics or inflammatory arthritis. ${ }^{5-7}$

Characteristic changes in OA includes progressive articular cartilage loss, increased subchondral plate thickness and sclerosis, osteophytes formation at joint margins and formation of subchondral bone cyst. Junctional zone between articular cartilage and subchondral bone is known as tired mark zone which is composed of calcified cartilage remnant. ${ }^{8-13}$

When the rate of damage exceeds the rate of repair, degeneration of the bone and cartilage ensues and the joint fails to effectively dissipate load. This results in a cycle of biomechanical loading and biochemical degeneration, where the shock-absorbing cartilage is progressively destroyed, exposing the bone to greater load and leading to bone damage (bone marrow lesions). ${ }^{14}$ This leads to further loss of cartilage, narrowing of the joint space (the space between the bones) and the overgrowth of bone (osteophyte formation), which causes hard lumps to develop around the joints. ${ }^{15-17}$

Cytokines associated with adipose tissue, include leptin, adiponectin and resist in have a evolving role in OA. ${ }^{18}$

Knee most common joint in OA cause significant disability impairs patient QOL (quality of life). ${ }^{19-}$ 20

For radiological diagnosis we use KellgrenLawrence Grading Scale.

The Kellgren and Lawrence system of classification was proposed by Kellgren et al. in 1957 and later accepted by WHO in $1961 .^{22}$ 


\begin{tabular}{|l|l|}
\hline Grade 0 & $\begin{array}{l}\text { No radiographic features of OA are } \\
\text { present }\end{array}$ \\
\hline Grade 1 & $\begin{array}{l}\text { Doubtful narrowing of joint space } \\
\text { (JSN) and possible osteophytic } \\
\text { lipping }\end{array}$ \\
\hline Grade 2 & $\begin{array}{l}\text { Definite osteophytes, definite } \\
\text { narrowing of joint space(JSN). }\end{array}$ \\
\hline Grade 3 & $\begin{array}{l}\text { Moderate multiple osteophytes, } \\
\text { definite narrowing of joints } \\
\text { space(JSN), sclerosis and possible } \\
\text { deformity of bone contour. }\end{array}$ \\
\hline Grade 4 & $\begin{array}{l}\text { Large osteophytes marked narrowing } \\
\text { of joint space, severe sclerosis and } \\
\text { definite deformity of bone contour }\end{array}$ \\
\hline Grade 5 & $\begin{array}{l}\text { Large osteophytes, marked JSN, } \\
\text { severe sclerosis and definite bony } \\
\text { deformity }\end{array}$ \\
\hline
\end{tabular}

\section{Biomechanics of Knee Joint in OA}

$\mathrm{OA}$ knee most common in medial TF compartment mainly effects the knee joint due to high varus forces during weight bearing activities such as walking. This varus torque is nearly 2.5 times the force through the lateral aspect of the knee which produces the varus deformity at knee in vicious manner. ${ }^{23}$

The external knee adduction moment distribute $60-80 \%$ of total intrinsic knee compressive load to the medial TF compartment, and people with medial TF OA tend to walk with larger knee adduction moments than normal subjects, resulting in increased medial compartment pressure. $^{24}$

The knee adduction moment is generated by the combination of the ground reaction force, which passes medial to the centre of the knee joint, and the perpendicular distance of this force from the centre of the joint. $^{25}$

Varus alignment of the lower limb theoretically increases the perpendicular distance of the ground reaction force from the centre of the knee joint, radiographic varus alignment is associated with the magnitude of the peak knee adduction moment in subjects with healthy and osteoarthritic knees. ${ }^{26}$ Knee joint laxity, which is defined as displacement or rotation of the tibia with respect to the femur, is another biomechanical variable argued to contribute to the pathogenesis of OA. One study showed that varus-valgus laxity is greater in the unaffected knees of patients with unilateral OA than in healthy control subjects. ${ }^{27}$

\section{Treatment}

The guidelines of Osteoarthritis Research Society International (OARSI) suggest that intervention should be progressive and proportional to disease severity. ${ }^{28}$

Non pharmacologic interventions include patient education, life style modification, weight loss, exercise, heat and cold therapy, physical therapy, and occupational therapy. Shock absorbing insoles, subtalar strapping and avoidance of high heels have mounting evidence in preventing lower extremity joint pain. $^{29}$

Currently available pharmacological therapy include analgesics (i.e. acetaminophen, cyclooxygenase, NSAIDS, tramadol). Along with this intra-articular corticosteroids and intraarticular hyaluronic acid also used for symptomatic osteoarthritis of the knee. ${ }^{30}$

Weight control, exercise and simple analgesics such as acetaminophen, are suggested as first-line tools for patient management in comparison to non-steroidal anti inflammatory drugs (NSAIDs). ${ }^{31}$

Economic burden of NSAIDS associated GIT disorder is enormous causes serious events. ${ }^{32}$

Glucocorticoids although has positive safety profile but has short term effect. ${ }^{33}$

\section{Viscosupplementation}

The concept of viscosupplementation, first proposed by Balazs ${ }^{34}$ is based on the hypothesis that intra-articular injection of hyaluronic acid into OA joints could restore the rheological properties of the SF, promote the endogenous synthesis of a higher molecular weight and possibly more functional hyaluronan, thereby improving mobility, articular function, and decreasing pain. ${ }^{35}$

Viscosupplementation with intra-articular HA promotes chondrocyte hyaluronic acid synthesis 
and prevents the additional degradation of cartilage and may promote cartilage regeneration. ${ }^{36}$ It is also postulated to diminish the production of inflammatory mediators and matrix metalloproteinase involved in osteoarthritis ${ }^{37}$. Viscosupplementation decline osteoarthritis symptoms in early osteoarthritis, and improves functional outcome, if other conservative treatment modalities are ineffective. Viscosupplementation relieves the symptoms of osteoarthritis of the knee, and this therapeutic effect may last several weeks. ${ }^{38-40}$

Hylan G-F 20 is one of the viscosupplementation product approved for marketing in Canada since 1992 and the United States since 1997 after public review of the data by a Food and Drug Administration (FDA) advisory panel. ${ }^{41}$

Hylan G-F 20 is unique in that the hyaluronan is chemically crosslinked. Hyaluronan is a longchain polymer containing repeating disaccharide units of Na-glucuronate-N-acetylglucosamine. ${ }^{42}$

\section{Hyaluronic Acid}

Synovial fluid is composed of polysaccharides, among other elements contain glucosamine, glucuronic acid and hyaluronic acid.

HA is a polysaccharide chain made of repeating disaccharide units of $\mathrm{N}$-acetyl glucosamine and glucuronic acid. Type B synoviocytes or fibroblast synthesize HA and secrete into joint space. HA has an anti-inflammatory effect, acts as a lubricant when movements in the joint are slow and as a shock absorber when movements are fast. ${ }^{43}$

Most articular HA composed of approximately 12,500 disaccharide units with MW of approximately 5x106 Daltons. Healthy human knee has $2 \mathrm{ml}$ of synovial fluid with HA concentration of 2.5-4 $\mathrm{mg} / \mathrm{ml}$. In OA knee reduction in $\mathrm{MW}$ and concentration of $\mathrm{HA}$ reduced to $1 / 2-1 / 3$. This causes decrease in viscous and elastic properties of synovial fluid. Loss of lubrication causes increase stress forces which further disrupt collagen network essential for articular surface integrity. ${ }^{44}$
Knee most common joint in OA cause significant disability impairs patient QOL (quality of life).

Knee OA negatively impacts socioeconomic factors as the associated disability leads to work performance and early retirement Principle of viscosupplementation pioneered by Balazs and co workers [Balazs 1982; Denlinger 1998; Peyron 1974; Weiss1999]

HA is a polysaccharide chain made of repeating disaccharide units of $\mathrm{N}$-acetyl glucosamine and glucuronic acid. Type B synoviocytes or fibroblast synthesize HA and secrete into joint space.

Most articular HA composed of approximately 12,500 disacharide units with MW of approximately 5x106 daltons. Healthy human knee has $2 \mathrm{ml}$ of synovial fluid with $\mathrm{HA}$ concentration of $2.5-4 \mathrm{mg} / \mathrm{ml}$. In OA knee reduction in MW and concentration of $\mathrm{HA}$ reduced to $1 / 2-1 / 3$. This causes decrease in viscous and elastic properties of synovial fluid. Loss of lubrication causes increase stress forces which further disrupt collagen network essential for articular surface integrity. [Watterson, John R.MD et al viscosupplementation: therapeutic mechanism and clinical potential in OA knee.

JAAOS- Sep-Oct 2000-vol 8-issue5-p277-284

Variable safety profiles b/w HA derived through biological form (Bio-HA) and avion derived (ADHA) which cause local IA reaction. ${ }^{45}$

HMW Hylan GF-20 is more elastoviscous, more anti-inflammatory properties, proteoglycan synthesis, pain relief and more joint lubrication as compared to low molecular weight $\mathrm{HA}^{46}$ Chondroprotection is most frequent mechanism reported followed by proteoglycan formation and GAG synthesis, anti-inflammatory mechanism subchondral and analgesic action. ${ }^{47}$

Aim

To assess the role of intra-articular viscosupplementation in early knee osteoarthritis. 
Objectives

Primary Objective

1) To compare the effect of intra-articular viscosupplements over conservative treatment in early osteoarthritis of knee.

\section{Secondary Objective}

1) To study the effect of intra-articular viscosupplementation in early osteoarthritis of knee.

2) To study the effect of conservative treatment in early osteoarthritis of knee.

3) To study adverse effect of intra-articular viscosupplements if any.

\section{Material and Methods}

Study was conducted in outpatient department of Sport's Injury Centre, VMMC and Safdarjung Hospital, New Delhi from May 2017 to April 2018. This study prospectively enrolled total of 100 patients diagnosed with early knee osteoarthritis above 30 years of age with symptomatic osteoarthritis and radiographic evidence of Kellgren-Lawrence Grade I or II after fulfilling the inclusion and exclusion criteria and signed inform consent given single intra-articular injections of Hylan GF-20. The patients were divided into two groups, A and B. Block randomization process was used where in 2 labelled envelopes determined group allocation. First subject picked one out of 2 envelopes and was allocated accordingly. Next subject was allocated the remaining envelope.

Group A (Control Group) received conservative treatment including NSAIDS+ home based exercises including quadriceps and VMO strengthening.

Group B patients received an addition al intervention in the form of viscosupplementation injection intrarticularly.

Type of Study - Prospective Interventional study Period of Study - Two years

Allocation - Computerized block randomization End point classification - Efficacy Study
Primary purpose - Treatment

Sample Size - The study observed the difference in mean outcome scores between groups was, with regard to knee pain, a visual analog scale (VAS) score of 3 points (95\% confidence interval [95\% $\mathrm{CI}],-6$ to 11 points); with regard to knee function. Taking these values as reference, the minimum required sample size with $90 \%$ power of study and 5\% level of significance is 39 patients in each study group. To reduce margin of error, total sample size taken was 100 (50 patients per group).

Formula used is:-

1) For comparing mean of two groups

$\mathrm{N}>=2$ ( standard deviation $) 2 *(\mathrm{Z} \alpha+\mathrm{Z} \beta) 2$

(mean difference) 2

Where $Z \alpha$ is value of $Z$ at two sided alpha error of $5 \%$ and $Z \beta$ is value of $Z$ at power of $90 \%$ and mean difference is difference in mean values of two groups.

\section{Inclusion Criteria}

Patients fulfilling all the following criteria were included:

1. Symptomatic patients with early knee osteoarthritis diagnosed clinically and radiologically.

Radiological investigation included- X-ray knee AP view and lateral view in standing position and Skyline view:

1) For assessing degree of osteoarthritis (Kellgren and Lawrence grading system)

2) To rule out malalignment

3) Patients between 35-55 years of age.

4) Patient prescribed viscosupplimentation in routine OPD.

5) Consent of the patient

\section{Exclusion Criteria}

1. Any ligamentous injury in the knee.

2. Any clinical instability or mechanical derangement.

3. History of trauma. 
4. Secondary osteoarthritis.

5. Patients with severe disease (Grade IV) per Kellgren-Lawrence criteria, or who had prior arthroplasty in the target knee.

6. Allergy to egg protein.

7. Intra-articular corticosteroid injection in last month

\section{Methodology}

Pre Procedural Workup: Data collection prior to intra-articular injection included detailed history, clinical examination and radiological evaluation of patients satisfying the inclusion criteria.
1) Age
2) Sex
3) Site of knee-right/left/bilateral
4) WOMAC score
5) To assess level of pain (VAS scoring)

Follow Up: 2, 4 and 12 week post intra-articular injection.

Primary outcome measure -VAS (Visual Analog scale)

Secondary Outcome measure-WOMAC

\section{Results}

Demographic Profile: A total of hundred patients between the age of 35 - 55 years were enrolled in this study which were divided in two groups. Patients from all socio-economic status and all professions were included in this study.

Gender Ratio: In this study each group contains 50 patients in which Group A contains 35 females $(70 \%)$ and 15 males (30\%) and group B contain 30 females (60\%) and 20 males (40\%)

\begin{tabular}{|ll|c|c|c|c|}
\hline & & A & B & Total & P value \\
\hline Sex & F & $70 \%$ & $60 \%$ & $65(65.00 \%)$ & \\
& M & $30 \%$ & $40 \%$ & $35(35.00 \%)$ & \multirow{2}{*}{0.295} \\
Total & & 50 & 50 & 100 & \\
& & $(100.00 \%)$ & $(100.00 \%)$ & $(100.00 \%)$ & \\
\hline
\end{tabular}

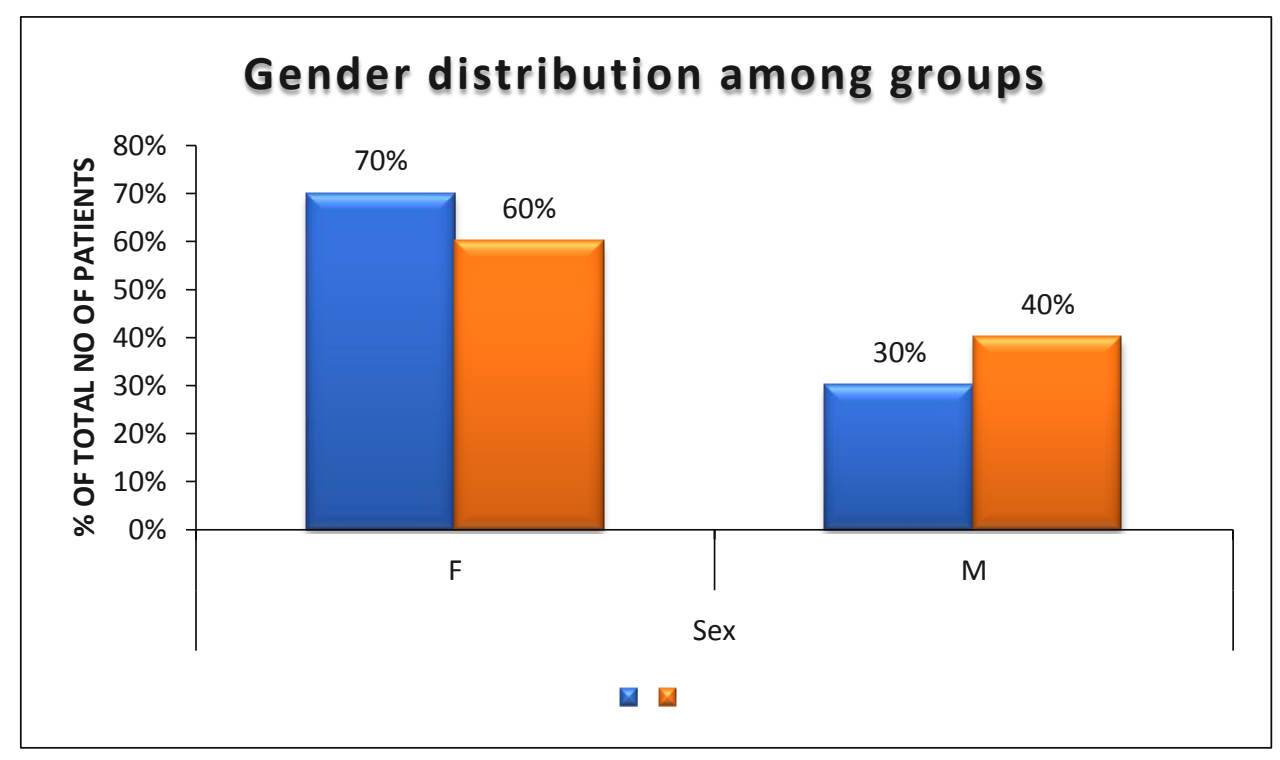

Age Distribution: Most of the patients belongs to age group of 35-55 years. In the group A $36 \%$ were of 35-45 age group and 54\% of 46-55 age group and in group B was 30\% were of 35-55 age group and $70 \%$ were of $46-55$ age group. 


\begin{tabular}{|lc|c|c|c|c|}
\hline & & A & B & Total & P value \\
\hline Age & $1) 35-45$ & $36 \%$ & $30 \%$ & $33(33.00 \%)$ & \\
& $2) 46-55$ & $64 \%$ & $70 \%$ & $67(67.00 \%)$ & \multirow{2}{*}{0.523} \\
Total & & 50 & 50 & 100 & \\
& & $(100.00 \%)$ & $(100.00 \%)$ & $(100.00 \%)$ & \\
\hline
\end{tabular}

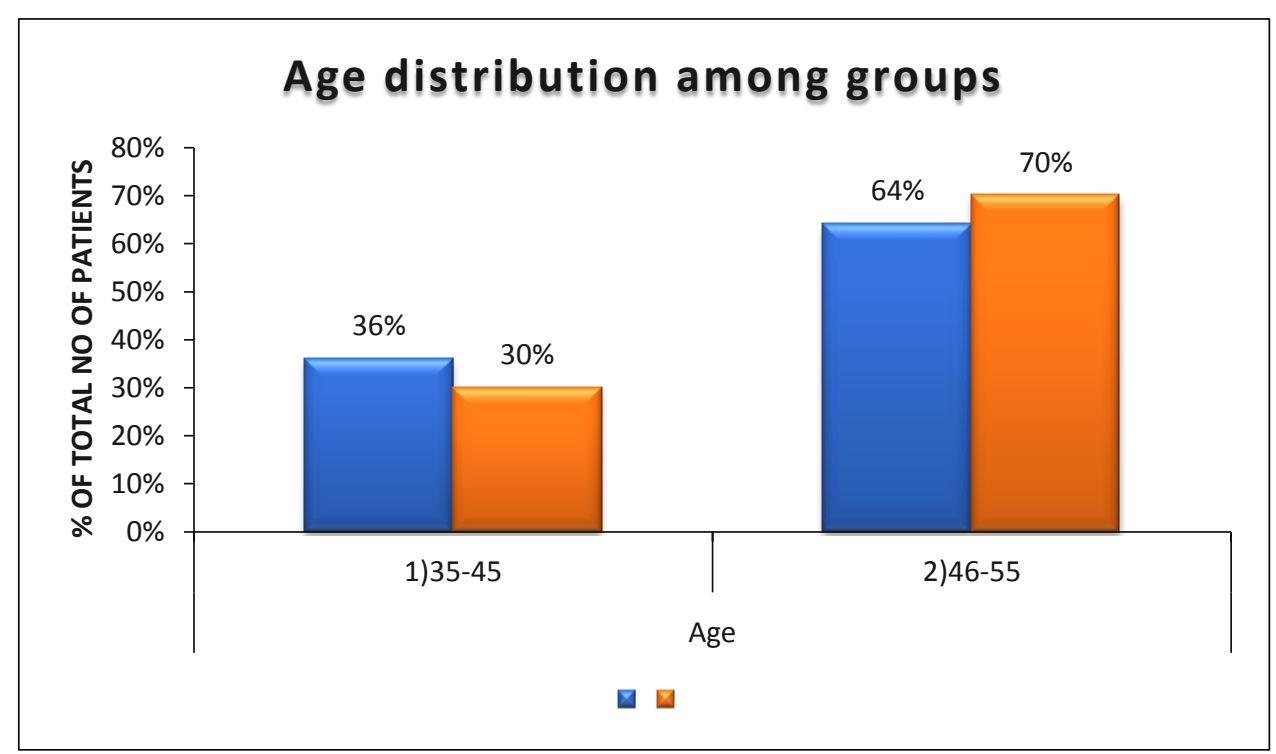

In the group A mean age was 48.02 and in group B was 48.18 .

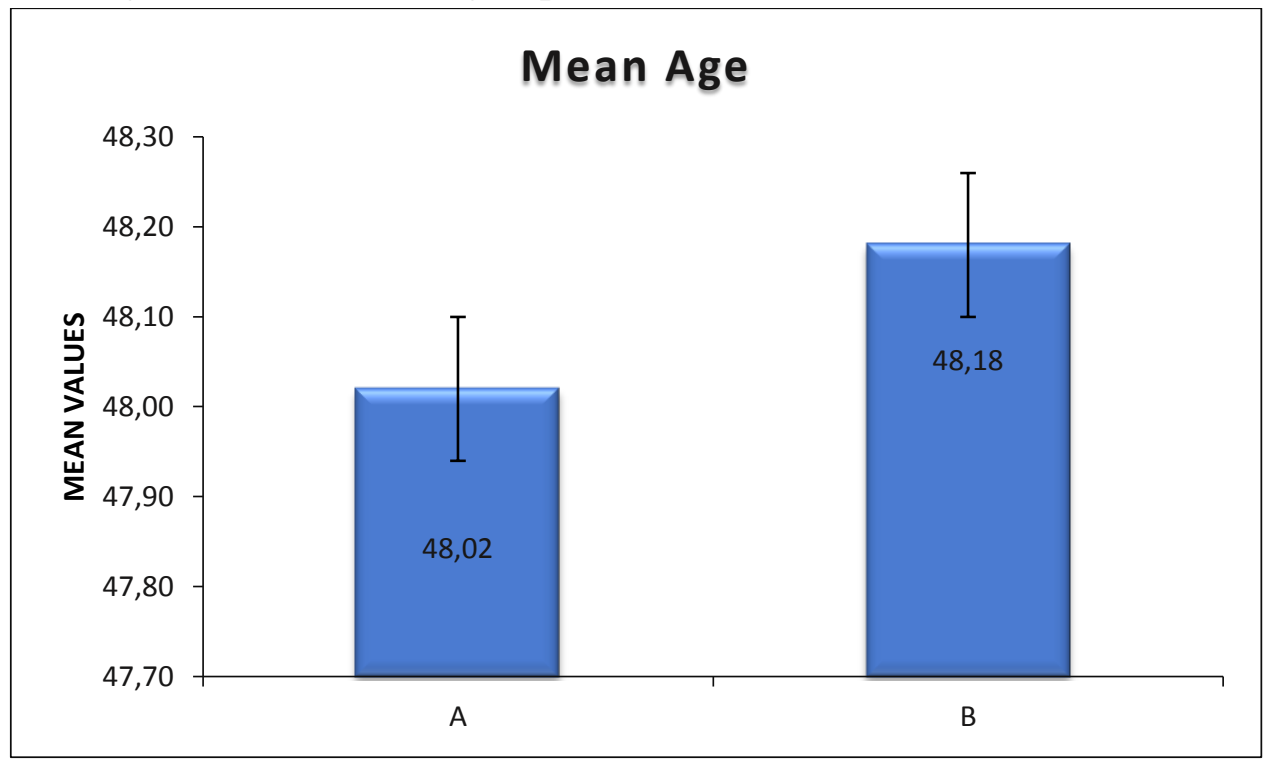

Kellgren and Lawrence Grading: In group A, 9 patients (18\%) were of grade 1 and $41(82 \%)$ were of grade 2 . In group B, 7 patients (14\%) belongs to grade 1 and 43 patients $(86 \%)$ belong to grade 2.

\begin{tabular}{|ll|c|c|c|c|}
\hline & & A & B & Total & P value \\
\hline Kl grade & 1.00 & $18 \%$ & $14 \%$ & $16(16.00 \%)$ & \\
& 2.00 & $82 \%$ & $86 \%$ & $84(84.00 \%)$ & \multirow{2}{*}{0.585} \\
Total & & 50 & 50 & 100 & \\
& & $(100.00 \%)$ & $(100.00 \%)$ & $(100.00 \%)$ & \\
\hline
\end{tabular}




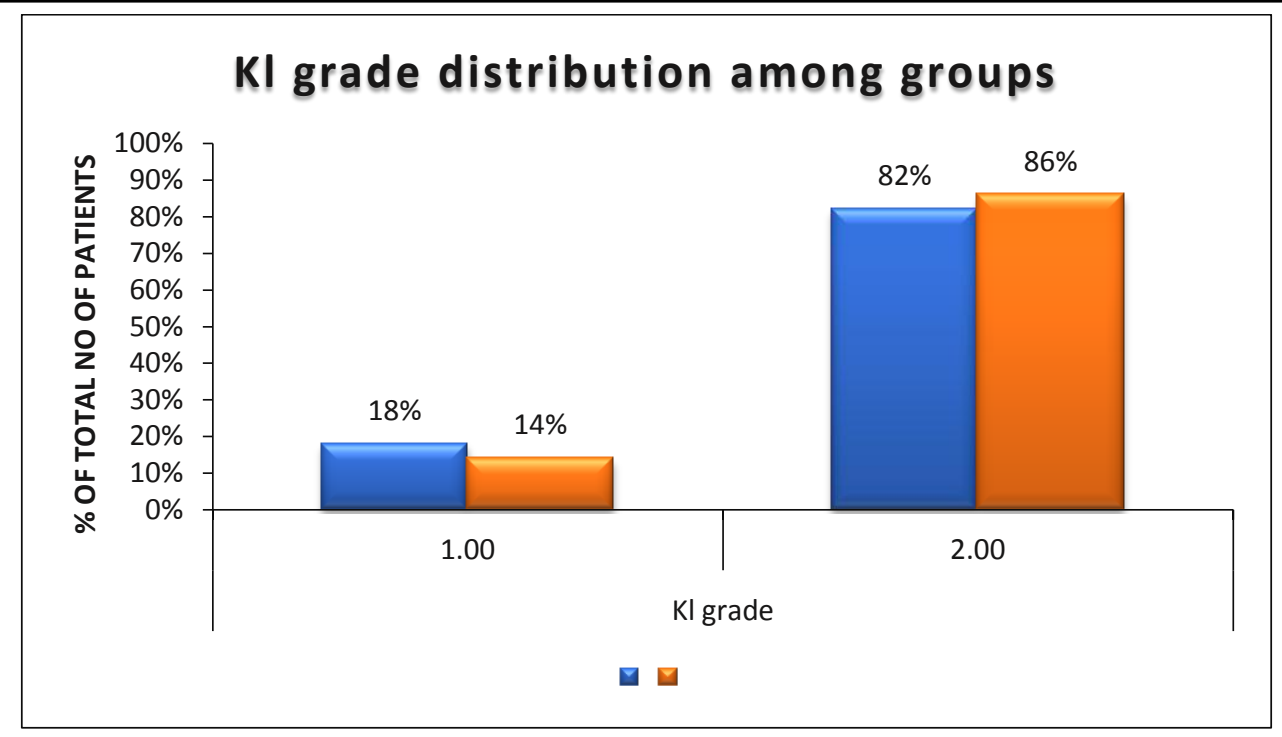

VAS Trend: At time of intervention the range of VAS in group A was $6 \pm 0.86$ which significantly reduces on further follow up at $2,4 \& 12$ weeks (5 $\pm 0.86,4 \pm 0.86$ and $3.24 \pm 0.89$ ). $\mathrm{P}$ value on comparing baseline to $2,4 \& 12$ weeks was < .0001 which can be taken as statistically significant. Subsequent comparison of 2-4 weeks, 2-12 weeks \& 4-12 weeks also shows the $\mathrm{P}$ value $<.0001$.

Similarly in group B mean value of VAS at time of intervention was $5.76 \pm 0.74$ which significantly reduces on further follow up at 2, 4
$\& 12$ weeks $(4.72 \pm 0.78,3.22 \pm 0.82$ and $2.18 \pm$ 0.66). $\mathrm{P}$ value on comparing baseline to $2,4 \& 12$ weeks was <.0001 which can be taken as statistically significant. Subsequent comparison of 2 -4 weeks, 2-12 weeks \& 4-12 weeks also shows the $\mathrm{P}$ value <.0001.

On comparing group A to group B there was no statistically significant difference found between the groups as $\mathrm{P}$ value $>.0005$ during $2^{\text {nd week }}$ but it become statistically significant at $4^{\text {th }}$ and $12^{\text {th }}$ week.

\begin{tabular}{|l|c|c|c|}
\hline Weeks & Group A VAS & Group B VAS & P Value \\
\hline 0 week & $6 \pm 0.86$ & $5.76 \pm 0.74$ & 0.183 \\
\hline 2 week & $5 \pm 0.86$ & $4.72 \pm 0.78$ & 0.128 \\
\hline 4 week & $4 \pm 0.86$ & $3.22 \pm 0.82$ & $<.0001$ \\
\hline 12 week & $3.24 \pm 0.89$ & $2.18 \pm 0.66$ & $<.0001$ \\
\hline
\end{tabular}

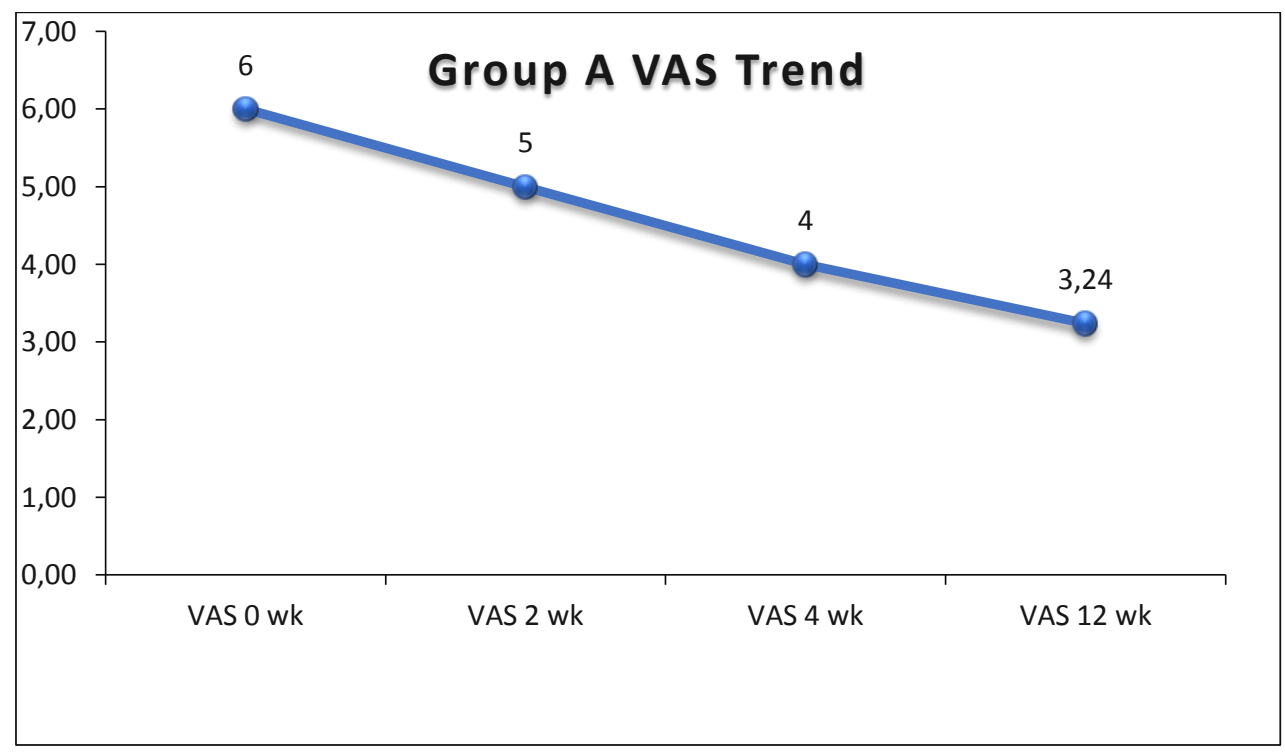



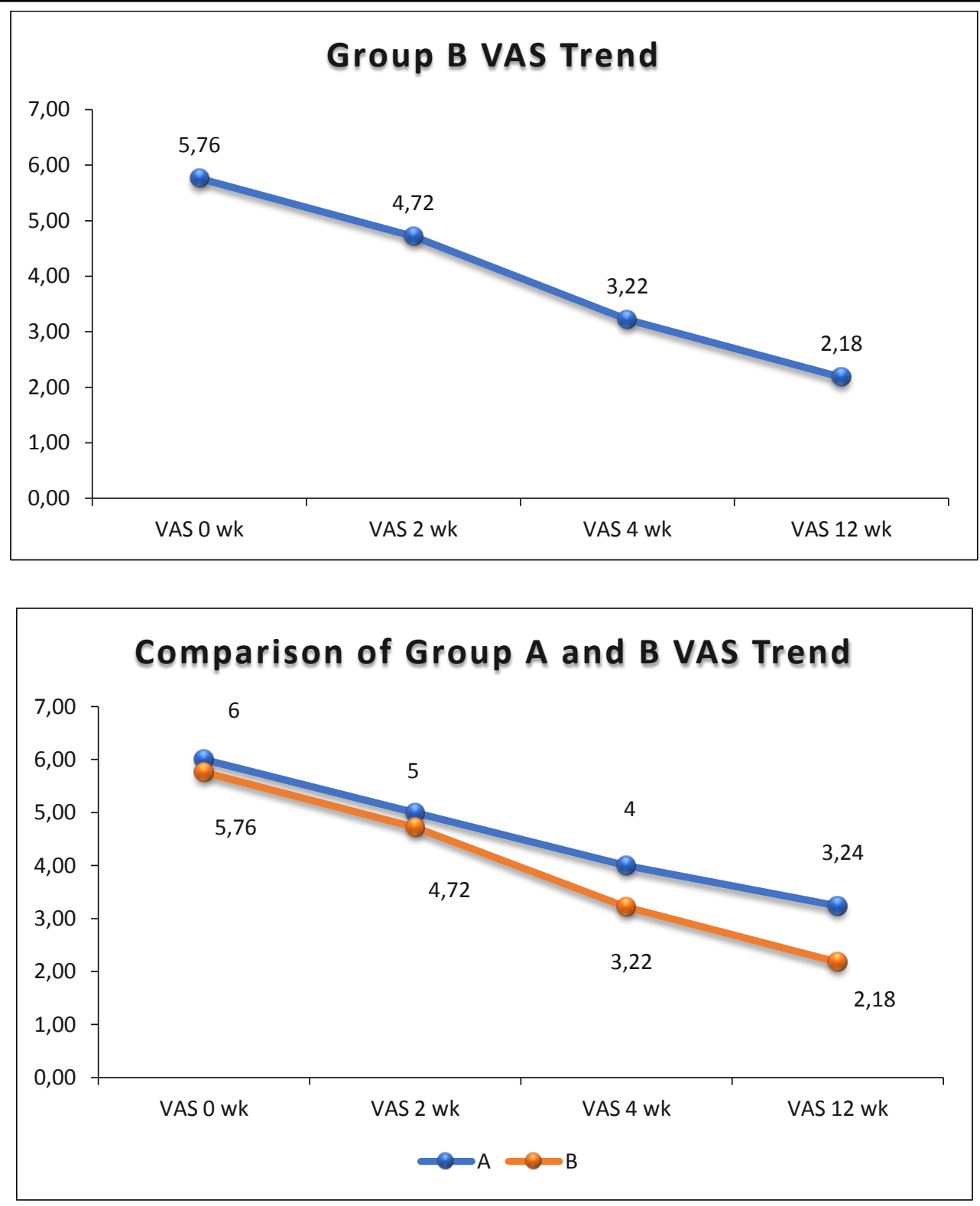

WOMAC Trend: At time of intervention the range of WOMAC in group A was $41.44 \pm 6.93$ which significantly reduces on further follow up at $2,4 \& 12$ weeks $(34.06 \pm 4.59,27.74 \pm 4.41$ and $22.76 \pm 4.19)$. P value on comparing baseline to 2 , $4 \& 12$ weeks was $<.0001$ which can be taken as statistically significant. Subsequent comparison of 2-4 weeks, 2-12 weeks \& 4-12 weeks also shows the $\mathrm{P}$ value <.0001.

Similarly in group B mean value of WOMAC at time of intervention was $41.12 \pm 3.99$ which significantly reduces on further follow up at 2, 4 $\& 12$ weeks $(37.8 \pm 4.62,29.88 \pm 3.48$ and $22.1 \pm$ 2.39). $\mathrm{P}$ value on comparing baseline to $2,4 \& 12$ weeks was < 0001 which can be taken as statistically significant. Subsequent comparison of 2- 4 weeks, 2-12 weeks \& 4-12 weeks also shows the $\mathrm{P}$ value <.0001.

On comparing group A to group B there was statistically significant difference found at 2 and 4 weeks in favouring of group B and it again became not significant at 12 weeks.

\begin{tabular}{|l|c|c|c|}
\hline Weeks & Group A WOMAC & Group B WOMAC & P Value \\
\hline 0 week & $41.44 \pm 6.93$ & $41.12 \pm 3.99$ & 0.942 \\
\hline 2 week & $34.06 \pm 4.59$ & $37.8 \pm 4.62$ & .0001 \\
\hline 4 week & $27.74 \pm 4.41$ & $29.88 \pm 3.48$ & 0.015 \\
\hline 12 week & $22.76 \pm 4.19$ & $22.1 \pm 2.39$ & 0.967 \\
\hline
\end{tabular}



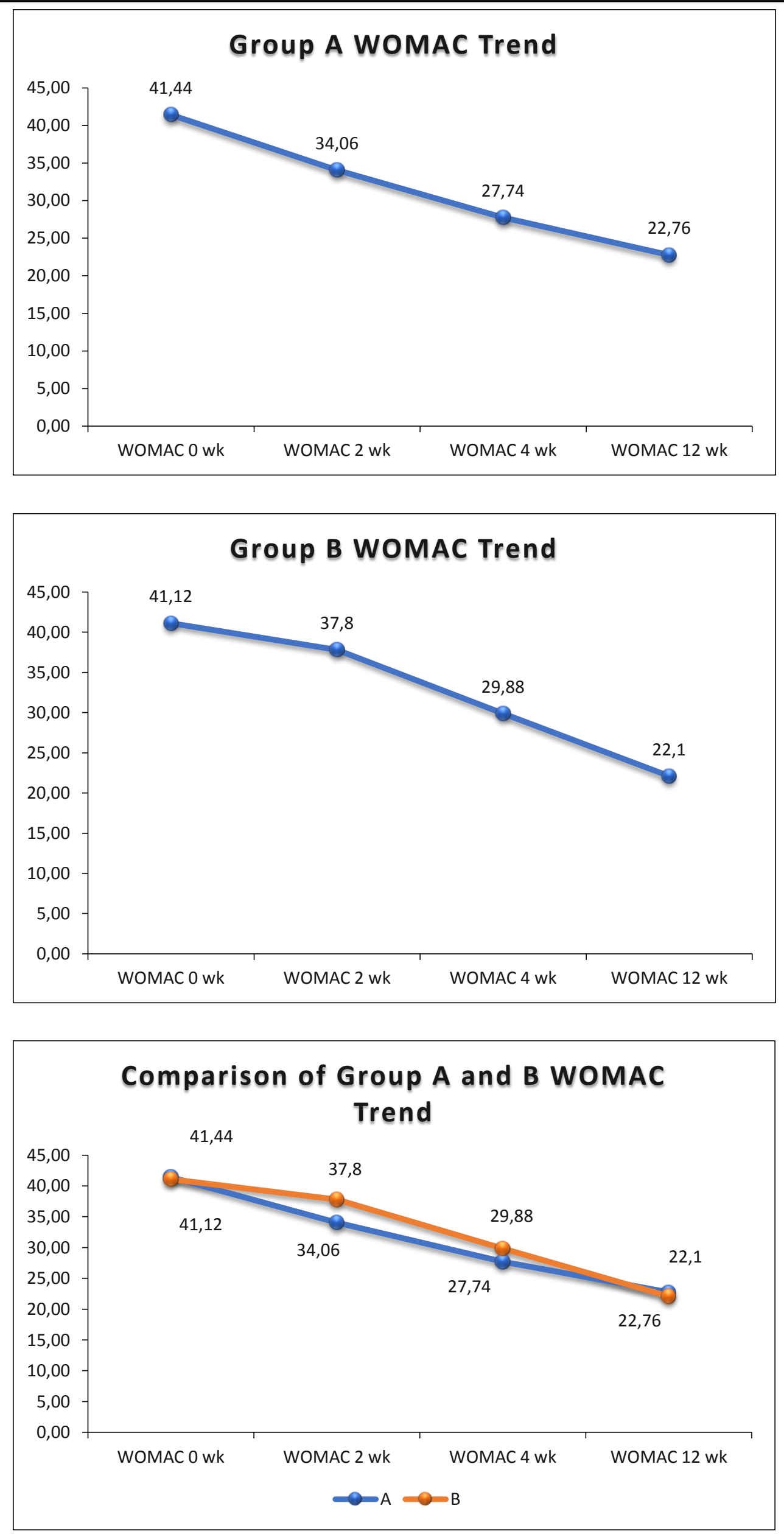


\section{Discussion}

Our first group, treated with conservative treatment (including NSAIDS thome based exercises including quadriceps and VMO strengthening), showed significant improvement at 2, 4 and 12 weeks follow up in both the parameter assessed (pain by using VAS, function by WOMAC). Pain was the primary outcome measure parameter and assessed by VAS.

From time of intervention the range of VAS in group A significantly reduces on further follow up at $2,4 \& 12$ weeks . Our study subjects show continued improvement at 12 weeks but not followed beyond that due to limitation of study design. WOMAC in group A also significantly reduces on further follow up at 2, 4 \& 12 weeks.

Second group consisted of additional intervention in the form of VS to the conservative treatment. Our concerned group of interest was the second group to see and show any improvement in VAS and WOMAC in group B compared to group A. There, no significant difference was found in terms of VAS during 2nd week but it become statistically significant at 4th and 12th week.

On comparing group A to group B there was statistically significant difference found at 2 and 4 weeks in favour of group B and it again became non significant at 12 weeks.

On the basis of our study we may conclude that addition of VS improves in pain and knee function in early weeks but this effect is plateaus off after 4 weeks.

It clearly indicates that VS in a form of additional treatment along with physiotherapy and pharmacotherapy may offer additional advantage in terms of pain improvement and functional improvement.

Our study has some limitations too. There was no placebo group and isolated group fior people receiving only VS injection due to time constraint for this thesis work.

Efficacy of VS was purely dependent on reported data obtained from patients in the form of filled.

As many patient presents with bilateral knee involvement and it is difficult to distinguish one knee from the other due to lack of assessment tools so only criteria to make the differentiation is radiographs of the $\mathrm{x}$-ray knee(standing) in both $\mathrm{AP}$ and lateral view. So based on KL grading system and VAS score for pain we divide patients. Hence in cases of bilateral knee involvement, we treat both knees with the same treatment regime.

Based on the outcomes of this study it may be recommended that further research to be done with longer duration of follow to see if there is any increase in efficacy and larger multicenter groups to be evaluated.

\section{References}

1. Lutzner J, Kasten P, Gunther KP, Kirschner S. Surgical option for patient with osteoarthritis of knee. Nat Rev Rheumatol. 2009;5(30):9-16.

2. Petrella RJ, Petrella M. A prospective, randomized, double-blind, placebo controlled study to evaluate the efficacy of intraarticular hyaluronic acid for osteoarthritis of the knee. J Rheumatol. 2006;33(5):951-956.

3. Cross M, Smith E, Hoy D, Nolte S, Ackerman I, Fransen M, Bridgett L et al. The global burden of hip and knee osteoarthritis: estimates from the global burden of disease 2010 study. Ann Rheum Dis. 2014;73(7):1323-30.

4. Chopra A. The COPCORD world of musculoskeletal pain and arthritis. Rheumatology (Oxford). 2013 Nov;52(11): 1925-8. .

5. March L, Smith EU, Hoy DG, Cross MJ, Sanchez-Riera L, Blyth F, Buchbinder R, Vos $\mathrm{T}$ et al. Burden of disability due to musculoskeletal disorders. Best Pract Res Clin Rheumatol. 2014;28(3):353-66.

6. Altman R, Asch E, Bloch D, Bole G, Borenstein D, Brandt K et al. Development of criteria for the classification and reporting of osteoarthritis. Classification of osteoarthritis of the knee. Diagnostic and Therapeutic Criteria Committee of the American 
Rheumatism Association. Arthritis Rheum. 1986;29(8):1039-10.

7. Moskowitz Rolannd W, Altman Roy D, Hochberg Marc C. Defining osteoarthritis for epidemiological purpose. In: Buckwalter Joseph A, Goldberg Victor M, Eds. Osteoarthritis: Diagnosis and Medical/ Surgical Management 4 th edition. London: Lippincot \&amp; Williams;2007:35-39.

8. Randall L Braddom, Leighton Chan, Mark A Harrast. Physical medicine \& rehabilitation. 4th ed.

9. Fractal signature analysis measures cancellous bone organisation in macro radiographs of patients with knee osteoarthritis. Ann Rheum Dis. 1996;55:749755.

10. Burr DB. Subchondral bone. In: Brandt KD, Lomander S, Doherty M (eds). Osteoarthritis. Oxford University Press, Oxford, UK. 1998:144-156.

11. Li B, Aspden RM. Mechanical and material properties of the subchondral bone plate from the femoral head of patients with osteoarthritis or osteoporosis. Ann Rheum Dis. 1997;56:247-254.

12. Bullough PG. The geometry of diarthrodial joints, its physiologic maintenance, and the possible significance of age-related changes in geometry-to-load distribution and the development of osteoarthritis. Clin Orthop Relat Res. 1981;156:61-66.

13. Bullough PG. The role of joint architecture in the etiology of arthritis. Osteoarthritis Cartilage. 2004;12:S2-9.

14. Kellegren Jh. Lawrence JS. Radiological assessment of osteoarthrosis. Ann Rheum Dis.1957 Dec;16(4):494 -502.

15. Sharma L, Song J, Felson DT, Cahue S, Shamiyeh E, Dunlop DD. The role of knee alignment in disease progression and functional decline in knee osteoarthritis. JAMA 2001;286:188-195.

16. Sharma L, Cahue S, Song J, Hayes K, Pai YC, Dunlop D. Physical functioning over three years in knee osteoarthritis: role of psychosocial, local mechanical, and neuromuscular factors. Arthritis Rheum. 2003;48:3359-3370.

17. Lohmander LS, Felson D. Can we identify a 'high risk' patient profile to determine who will experience rapid progression of osteoarthritis? Osteoarthritis Cartilage. 2004;12:S49-52.

18. Sowers MR, Karvonen-Gutierrez CA. The evolving role of obesity in knee osteoarthritis. Curr Opin Rheumatol, 2010 Sep;22(5):533-7.

19. Registrar General and census commission of India, Census of India, 2001http://www.censusindiagov.in.

20. Felson DT, Zhang Y, Hannan MT, Naimark A, Weissman B, Aliabadi P, Levy D. Risk factors for incidence knee OA elderly .Framingham study. Arthritis Rheum. 1997;40:728-33.

21. Altman R, Asch E, Bloch D, Bole G, Borenstein D, Brandt K et al. Development of criteria for the classification and reporting of osteoarthritis. Classification of osteoarthritis of the knee. Diagnostic and Therapeutic Criteria Committee of the American Rheumatism Association. Arthritis \&amp; Rheumatism. 1986;29(8):1039-10.

22. Kellegren Jh. Lawrence JS. Radiological assessment of osteoarthrosis. Ann Rheum Dis.1957 Dec; 6(4):494 -502.

23. Sharma L, Hurwitz DE, Thonar EJ, Sum JA, Lenz ME, Dunlop DD, Schnitzer TJ, KirwanMellis G, Andriachchi TP. Knee adduction moment, serum hyaluronan level, and disease severity in medial tibiofemoral osteoarthritis. ArthritisRheum. 1998;41:1223-40.

24. Miyazaki T, Wada M, Kawahara H, Sato M, Baba H, Shimada S. Dynamic load at baseline can predict radiographic disease progression in medial compartment knee osteoarthritis. Ann RheumDis. 2002;61:617-22.

25. Andriacchi TP, Dynamics of knee malalignment. Orthop Clin North Am. 1994;25:395-403. 
26. Hurwitz DE, Ryals AB, Case JP, Block JA, Andriachhi TP. The knee adduction moment during gait in subjects with knee osteoarthritis is more closely correlated with static alignment than radiographic disease severity, toe out angle and pain. J Orthop Res. 2002;20:101-7.

27. Sharma L, Song J, Felson DT, Cahue S, Shamiyeh E, Dunlop DD. The role of knee alignment in disease progression and functional decline in knee osteoarthritis. JAMA. 2001;286:188-95.

28. Zhang W, Moskowitz R W, Nuki G, Abramson S, Altman RD, Arden $\mathrm{N}$ et al. OARSI recommendation for management of hip and knee OA, Part 2: OARSI evidencebased, expert consensus guidelines. OA cartilage.2008;16(02):137-162.

29. Amy Wagner, Sarah Luna. Effect of footwear on joint pain and function in older adults with lower extremity osteoarthritis. J Geriatr Phys Ther.2016;41(2):85-101.

30. American Academy of Orthopaedic Surgeons. Treatment of Osteoarthritis of the Knee. 2013 [Updated 2013 July 8].

31. Smith MM, Cake MA, Ghosh P, Schiavinato A, Read RA, Little CB: Significant synovial pathology in a meniscectomy model of osteoarthritis: modification by intra-articular hyaluronan therapy. Rheumatology (Oxford). 2008;47(8):1172-1178.

32. Bannuru RR, Natov NS, Obadan IE, Price LL, Schmid CH, McAlindon TE. Therapeutic trajectory of hyaluronic acid versus corticosteroids in the treatment of knee osteoarthritis: a systematic review and metaanalysis. Arthritis Rheum. 2009;61(12):170411.

33. Habib GS. Systemic effects of intra-articular corticosteroids. Clin Rheumatol. 2009;28(7): 749-56.

34. Balazs EA, Denlinger JL. Viscosupplementation: A new concept in the treatment of osteoarthritis. J Rheumatol. 1993;39:3-9.
35. Peyron JG, Balazs EA. Preliminary clinical assessment of Na-hyaluronate injection into human arthritic joint. Pathol Biol (Paris). 1974;22:731-6.

36. Yuanyuan Wang, Stephen Hall, Fahad Hanna, Anita E Wluka, Gail Grant, Paul Marks et al. Effects of hylan GF-20 supplementation on cartilage preservation detected by magnetic resonance imaging in osteoarthritis of knee: a two year single-blind clinical trial. BMC Masculoskeletal Disorders. 2011;12:195.

37. Axe JM, Snyder-Mackler L, Axe MJ. The role of viscosupplementation. Sports Med Arthrosc. 2013;21:18-22.

38. Chevalier X, Jerosch J, Goupille P, van Dijk N, Lutyen FP, Scott DL et al. Single, intraarticular treatment with $6 \mathrm{ml}$ hylan G-F 20 in patients with symptomatic primary osteoarthritis of the knee: a randomised, multicentre, double-blind, placebo controlled trial. Ann Rheum Dis. 2010;69:113-9.

39. Conrozier T, Jerosch J, Beks P, Kemper F, Euller-Ziegler L, Bailleul F, Chevalier X. Prospective, multi-centre, randomised evaluation of the safety and efficacy of five dosing regimens of viscosupplementation with hylan G-F 20 in patients with symptomatic tibio-femoral osteoarthritis: a pilot study. Arch Orthop Trauma Surg. 2009;129:417-23.

40. Raman R, Dutta A, Day N, Sharma HK, Shaw CJ, Johnson GV. Efficacy of hylan G-F 20 and sodium hyaluronate in the treatment of osteoarthritis of the knee: a prospective randomized clinical trial Knee. 2008;15(4):318-24.

41. Devesh Kapoor, Chaitali Lad, Ruchi Vyas, Manish Patel. An overview of viscosupplements: Therapeutic modality for ailment of osteoarthritis. Journal of drug delivery and therapeutics. 2016; vol6,no 4.

42. Sarvajeet Pal, SreedharThuppal, K.J Reddy, SachinAvasthi, AnishAggarwal, Himanshu Bansal, Senthilnathan Mohanasundaram, Francois Bailleul. Long -Term (1 - Year ) 
safety and efficacy of a single $6-\mathrm{mL}$ injection of Hylan G - F 20 in Indian patients with symptomatic knee osteoarthritis. The Open Rheumatology Journal. 2016;18743129.

43. Adae O Amoako and George Guntur A Pujalte. Osteoarthritis in young, active and arthritic individual. CLIN Med Insights Arthritis Musculoskelet Disord. 2014;7:2732.

44. Watterson, John R.MD, Esdaile, John M. Viscosupplementation: therapeutic mechanism and clinical potential in OA knee.JAAOS. sep-oct 2000;8(5):277-284.

45. Goldberg VM, Coutts RD. Pseudoseptic reactions to hylan viscosupplementation: diagnosis and treatment. Clin Orthop Relat Res. Feb 2004;419:130-7.

46. Ferdinando Priano. Early efficacy of intraarticular HYADDR4 (Hymovisc R) injection for symptomatic knee OA. Joints. 2017 Jun; 5(2):79-84.

47. American Academy of Orthopaedic Surgeons. Treatment of osteoarthritis of the knee: Evidence-Based Guideline. 2013. [Accessed April 15, 2016]. Journal of American Academy of Orthopaedic Surgeon. September 2013; vol 21(9):577-579.

48. Henderson EB, Smith EC, Pegley F, Blake DR. Intra-articular injections of $750 \mathrm{kD}$ hyaluronan in the treatment of osteoarthritis: a randomized single centre double-blind placebo-controlled trial of 91 patients demonstrating lack of efficacy. Ann Rheum Dis. 1994;53:529-34.

49. Lohmander LS, Dalén N, Englund G, Hämäläinen $\mathrm{M}$, Jensen $\mathrm{EM}$, Karlsson $\mathrm{K}$, Odensten M, Ryd L, Sernbo I, Suomalainen O,Tegnander A. Intra-articular hyaluronan injections in the treatment of osteoarthritis of the knee: a randomised, double blind, placebo controlled multicentre trial. Ann Rheum Dis. 1996 July;55(7):424-31.
50. Nicolas S. Piuzzi, Ronald J. Midura, George F. Muschler, Vincent C. Hascall. I Ahyaluronan injection for the treatment of OA. Perspective for mechanism of action. Ther Adv Musculoskel et al Dis 2018;10(2):55-57

51. Job Hermans, Max Reijman, Lucas M.A. Goossens, Hennie Verburg, Sita M.A. Bierma-Zeinstra, Marc A. Koopmanschap. Cost utility analysis of high molecular weight hyaluronic acid for knee osteoarthritis in everyday clinical care: an economic evaluation of randomized clinical trial. Arthritis Care \& Research 2018;vol70(1):8997.

52. Adae O Amoakoand George Guntur A Pujalte. Osteoarthritisin young, active and arthritic individual. Clin Med Insights Arthritis Musculoskelet Disord.2014;7:27-32

53. Jevsevar D, Donnelly P, Brown GA, Cummins Ds. Viscosupplementation for osteoarthritis of knee: a systemic review of evidence. J Bone Joint Surg Am. 2015 dec;97(24):2047-60.

54. Eric N. Bowman, Justin D. Hallock, Thomas W. Throckmorton, Fredrick M. Azar. Hyaluronic acid injection of the knee: predictor of successful treatment. Orthopaedic Journal of Sports Medicine. 2017 Jul;5 (7suppl6). 